\title{
The compilation of marine environmental spectrum for Carbon Fiber/Polymer Composites
}

\author{
$\mathrm{Xu}$ Liu \\ Qingdao Branch of Naval Aeronautical Engineering \\ University \\ Qingdao,China \\ liuxulwl@126.com \\ Yueliang Chen \\ Qingdao Branch of Naval Aeronautical Engineering \\ University \\ Qingdao,China \\ cy10532@sina.com \\ Wujun Huo \\ Qingdao Branch of Naval Aeronautical Engineering \\ University \\ Qingdao,China \\ 18953249067@163.com
}

\author{
Dongdong Wang \\ Qingdao Branch of Naval Aeronautical Engineering \\ University \\ Qingdao,China \\ wangliwlwl@126.com \\ Yuanling Lei \\ Qingdao Branch of Naval Aeronautical Engineering \\ University \\ Qingdao,China \\ 641721578@qq.com
}

\begin{abstract}
Affected by environment elements ,the degeneration of mechanical property for Carbon Fiber reinforced Polymer Composites(CFRP) under marine environments is an important engineering problem, and the key segment on solving this problem is how to reappear the aging course of CFRP in marine environment truly and quantitatively. Based on the analysis of aging mechanism of CFRP and characteristics of marine environment ,the significant environment elements that effect the aging of CFRP were determined, the simplifying and treating method of marine environment data were presented, the dynamic environment data of certain sea area was treated by MATLAB software and the marine environmental spectrum of certain sea area that applicable for CFRP was compiled.
\end{abstract}

Keywords-Carbon Fiber/Polymer Composites; aging; marine environmental spectrum; compilation

\section{INTRODUCTION}

The changing rule of the Marine environment factor spectrum describes the aging intensity and course that structural materials go through in the aircraft service environment. It's also the basis of optimization of material selection, mechanics performance prediction, corrosion(or aging)life control and protection system design under the Marine environment. According to the requirements in America's 《Aircraft Construction General Specification MIL-A-87221》 and the National Military Specifications 《The Outline of Military Aircraft Structural Integrity》, "In the design phase, the compiled design-use load and environment spectrum has to be used to do some preliminary durability or fatigue analysis and fatigue test, then choose the structural materials, determine the structure form and detail design, develop some technical measures for anticorrosion and give the target's design service life. While finalize the design, the given load and environment spectrum also should be used to do some durability and damage tolerance test, for the determination of economic life and maintenance cycle."Thus it can be seen that the environment spectrum as well as the load spectrum of plane using, is significant to determine the service life of the aircraft structure and ensure the flight safety. At present, research on the environment spectrum of plane using compiling is mainly based on the metal electrochemical corrosion mechanism, while the one based on the aircraft composite materials aging mechanism is rare. In this paper, research on the using environment spectrum of aircraft structure composite materials has been done, with the meteorological hydrological data that the captain's meteorological observatory collected, and eventually developed the spectrum of the Marine environment factors for the specific area.

\section{THE AGING MECHANISM ANALYSIS OF CFRP}

The corrosion of metal structure materials on active service aircraft is mainly caused by electrochemical reaction, which has been recognized by most scholars at home and abroad. Compared with the corrosion mechanism of metal structure, aging of Carbon Fiber Reinforced Polymer is much more complicated. Since the carbon fiber has good medium resistance and chemical stability, and it's the cathode of the galvanic couple after accidentally metal collision, metal's corrosion rate is being 
accelerated a lot, while the corrosion of carbon fiber is often very little or not at all. So the main consideration of Carbon fiber reinforced polymer matrix composites' aging is the aging of polymer matrix composites. Most scholars believe that spread and penetration are the basic motivation for the aging damage of polymer matrix. As for polymer materials, swelling and dissolving, chemical degradation and oxidation, hydrolysis, resulting from the spread and penetration of its surrounding reagent(like gas or liquid) towards the insides material, are the major form of materials' aging damage. The occurrence of aging form has a close relationship with environmental factors, the corresponding relationship between polymer's common forms of aging(corrosion) and environmental conditions is shown in table 1:

TABLE I. Corrosion Of Polymer Materials And Corresponding Environment

\begin{tabular}{|c|c|c|}
\hline \multicolumn{2}{|c|}{ Environmental conditions } & Corrosion forms \\
\hline $\begin{array}{c}\text { Chemical factors } \\
\text { Oxygen } \\
\text { Oxygen }\end{array}$ & $\begin{array}{c}\text { Other factors } \\
\text { Moderate temperature }\end{array}$ & $\begin{array}{c}\text { Chemical oxidation } \\
\text { Photocatalytic oxidation }\end{array}$ \\
Uater and aqueous solution & At room temperature & hydrolysis \\
Oxygen/moisture from the atmosphere & At room temperature & weathering \\
Water or moisture & microbial & Biological corrosion \\
Water or moisture & heat & pyrolysis \\
Water or moisture & radiation & Radiation decomposition \\
\hline
\end{tabular}

Chemical reactions of the main aging forms are shown as follows:

Thermal degradation is mainly divided into four stages:

(1) chain triggers:

$$
\begin{aligned}
& \mathrm{RH} \rightarrow \mathrm{R}^{-}+\mathrm{H}^{-} \quad \mathrm{R}^{-}+\mathrm{O}_{2} \rightarrow \mathrm{ROO}^{-} \\
& \text {(1) chain grows: } \\
& \text { (2) } \mathrm{ROO}^{-}+\mathrm{RH} \rightarrow \mathrm{ROOH}+\mathrm{R}^{-}
\end{aligned}
$$

(2)

$$
\begin{aligned}
& \text { (3) chain branches: } \mathrm{ROOH} \rightarrow \mathrm{RO}^{+}+\mathrm{OH}^{-} \\
& \mathrm{RO}^{+}+\mathrm{RH} \rightarrow \mathrm{ROH}+\mathrm{R}^{+} \\
& \mathrm{OH}^{-}+\mathrm{RH} \rightarrow \mathrm{H}_{2} \mathrm{O}+\mathrm{R}^{-}
\end{aligned}
$$

(4) chain ends: Radical polymerization produce Inert product.

Oxidative cracking reaction is shown as formula 4:

$$
\mathrm{R}^{*} \mathrm{H}+\mathrm{O}_{2}+\mathrm{H}_{2} \mathrm{O} \rightarrow \mathrm{H}_{2} \mathrm{O}_{2}+\mathrm{RH}
$$

The product $\mathrm{H}_{2} \mathrm{O}_{2}$ will cause the oxidative cracking of polymer molecular chain.

Hydrolysis reaction is shown as formula 5:<smiles>[R]O[PH+]OC([R])=O</smiles>

Dissolve the decomposition is shown as formula 6;

$$
R-C-X-R+Y Z \rightarrow R-C-X-Z+Y-C-R
$$

$\mathrm{YZ}$ in the formula is chemical solvent(such as water, alcohol, ammonia, hydrazine, etc.), $\mathrm{X}$ refers to the impurity atoms which are non-carbon atoms, such as $\mathrm{O}, \mathrm{N}$, $\mathrm{Si}, \mathrm{P}, \mathrm{S}$ and halogen, etc.

\section{THE SELECTION OF SIGNIFICANT \\ ENVIRONMENTAL FACTORS AND THE COLLECTION OF MARINE ENVIRONMENT DATA}

\section{A. The selection of significant environmental factors}

So far, limited by the research level of Composite material aging mechanism, a unified understanding on the environmental factors that can influence the aging of composite materials structure has not yet been formed. In this paper, based on the analysis of the mechanism of the composite material aging, and with comprehensive consideration of the characteristics of aircraft service Marine environment, the significant factors that have an impact on aircraft composite material structure aging are selected as follows: temperature, relative humidity, rainfall and ultraviolet radiation. And the environment spectrum will be compiled by getting the intensity, duration, frequency, and joint action of each factor.

(1)Temperature

Under the hot and humid environment, temperature has a significant impact on the moisture absorption process of composite material, increase of temperature will hugely speed up the moisture absorption rate, while the change of temperature also will change the residence time of surface water film. Simple temperature increase only can aggravate the degree of composite material's light oxygen aging and heat oxygen aging, without wet and heat aging rate increasing at all. Only under the condition of high temperature and high humidity, will the moisture absorption damage rate accelerate.

(2)Relative humidity

The composite material under the condition of humid atmosphere manly absorbs the moisture from air with the method of spread, causing moisture absorption damage. The equilibrium amount of moisture absorption under specific damp environment is the characterization of the degree of the aging composite material. Research shows that the equilibrium amount of moisture absorption of the composite material has little relationship with temperature. 
For most composite material system, while assuming that the equilibrium amount of moisture absorption of the composite material is only associated with relative humidity, it will present a linear increase along with the increase of relative humidity. Thus, the aging degree of composite material increases along with relative humidity's increase.

\section{(3)Rainfall}

The amount of rainfall indicates the action intensity itself. The rain can wash away pollutants on the composite material structure surface that exposed to the external environment. It also can penetrate into material, causing some inside water soluble substances, plasticizer and material containing hydrophilic group(like hydroxyl and carboxyl) dissolved, extracted or absorbed by water, resulting in the accelerated aging of material. What's more, rain penetrating into the gap of plane structure with imperfect seal measures also will increase local environment humidity as well as action time and aggravate aging degree.

(4)Ultraviolet radiation

In Marine environment, the direct light of sun will cause oxygen aging and hot oxygen aging of composite material. Visible light and infrared contained in sunshine will be absorbed by the polymer composite materials and turned into heat energy, the resulting oxidation is called hot oxygen aging; The Photocatalytic oxidation process caused by ultraviolet radiation and oxygen is called light oxygen aging. Though very little, ultraviolet radiation has extremely high energy, and it's very sensitive to material. So among the two kinds aging form, light oxygen aging caused by ultraviolet radiation is the major one.

\section{B. The collection of Marine environment data}

Differing from the method that setting up climate test station and doing environment static data acquisition, in order to truly simulate the aging process that plane composite material structure suffers from service in Marine environment, the way of ship dynamic environment data collection has been used for the first time to collect all environmental data on shipping routes during 2009--2014.Typical courses in the area are shown as fig.1.The shaded part represents land while the rest represents sea, and the navigation sequence is A,B,C,D,E,F.....W,X,Y, mark a group of latitude and longitude coordinates every 30 hours, drawn up by 25 time node within the month. It can be seen that the difference between each day's sailing linear distance, sometimes a one-day voyage crosses several longitude or latitude. It can more truly simulate the change of corrosion environment that happens during the process of aircraft service.

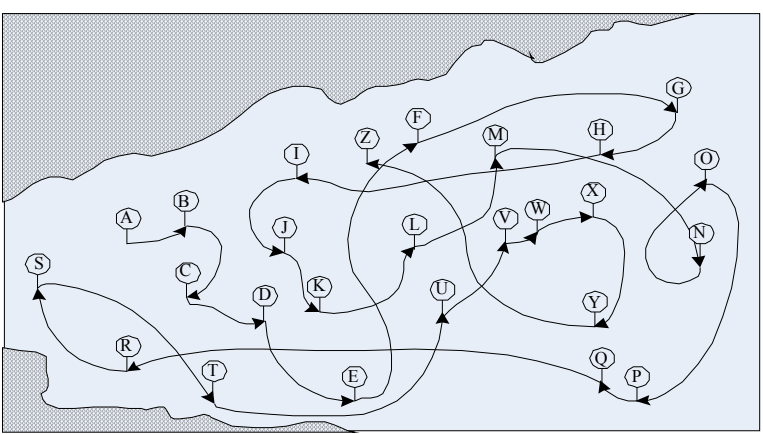

Figure.1 The typical path of collection for environmental data

\section{THE METHODS AND PROCESSES OF MAKING UP SPECTRUM}

\section{A. establish the Marine environment database}

Establish the environment meteorological database with the meteorological data of some area that collected by ship weather stations as original materials. Environmental data includes the temperature at four time points(T2,T6,T14,T20)of each day, the four corresponding relative humidity(T2,T6,T14,T20), wind speed and direction, wave height, rainfall, weather conditions as well as the parameters like daily average temperature, humidity, precipitation, rainfall frequency, illumination time, solar radiation and speed and direction of the area in the past 6 years, what's more, the detailed temperature and humidity value per hour in 2009 is also included.

Data above reflects the month, season, year change rule of meteorological environment factors in the specific area such as temperature, relative humidity, rainfall, sun radiation, wind speed and direction, etc. The establishment of environment data base is able to reflect local annual weather conditions, it also can prepare a good foundation of further setting up and improving plane Marine environment spectrum.

\section{B. Simplification and processing of environment} data.

In the whole service life of the aircraft, the various environment factors have a very long effect on the plane structure, not only the change of the spectrum, but also the length of action time. If required that the compiling environment spectrum fully describe all the change course of environment factors, which means be synchronous with the calendar life, this kind of environment spectrum being applied to artificial reproduction is not only difficult to achieve technically, but also meaningless being the same length of calendar life. In order to achieve the engineering practice reproduction of the aging effect that environment factors have on aircraft composite structure, simplification and filter of environment factors must be finished.

(1)Simplification and processing of humidity data

Reports on the critical value of relative humidity of composite material haven't been found so far. According to relevant literature, when it comes to aircraft composite structure, generally the relative humidity is $85 \% \mathrm{RH}$ under the worst situation, while $53.1 \% \mathrm{RH}$ yearly under the most moderate situation(in a typical environment dry and cold 
areas).In this paper, choose the approximate mean $70 \%$ as the reference value of the critical value of relative humidity, consider $\mathrm{RH}<70 \%$ as in dry air environment.

(2)Simplification and processing of temperature data

When the environment temperature is below $0^{\circ} \mathrm{C}$, the change of environmental temperature has little impact on the aircraft composite structure aging, so set $0^{\circ} \mathrm{C}$ as the lower limit of the critical value of temperature, which means saving values above $0^{\circ} \mathrm{C}$ and eliminating values below $0^{\circ} \mathrm{C}$. Since other factors has different impact on structure aging under different temperature when relative humidity is higher than $70 \%$, compile respectively the corresponding rainfall duration and frequency and action time when relative humidity is higher than $70 \%$ at 7 temperature rating: $5^{\circ} \mathrm{C}, 10^{\circ} \mathrm{C}, 15^{\circ} \mathrm{C}, 20^{\circ} \mathrm{C}, 25^{\circ} \mathrm{C}, 30^{\circ} \mathrm{C}, 35^{\circ} \mathrm{C}$.

(3)Simplification and processing of rainfall data

Save the rainfall data above $0^{\circ} \mathrm{C}$, and eliminate the others below $0{ }^{\circ} \mathrm{C}$. radiation

(4)Simplification and processing of ultraviolet

According to the daily radiation, month total radiation and total annual radiation of the light from the sun during the test given by meteorological data statistics, do the further integration of data in past years and then get the average annual amount of radiation. Also, the average amount of ultraviolet radiation can be got according to the proportion of ultraviolet radiation in the sun light on the deck(shown in fig.2, the wavelength ranges from $290 \mathrm{~nm}$ to $400 \mathrm{~nm}$ is ultraviolet radiation), temporarily take $7 \%$, which is the ultraviolet radiation spectrum in the area.

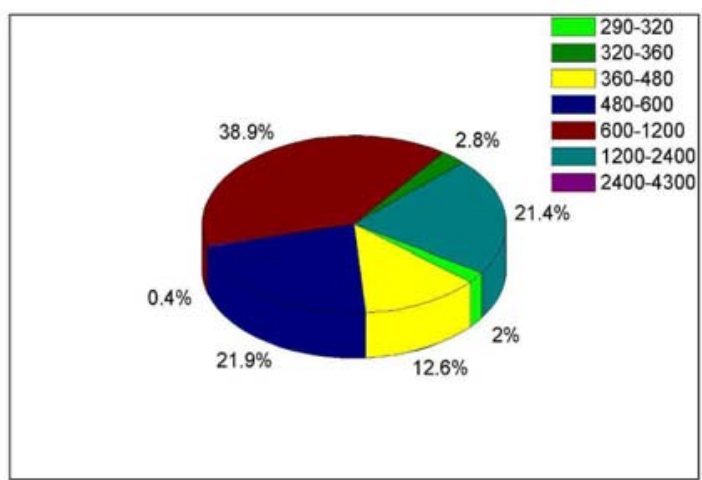

Figure.2 The ratio of ingredients for sunlight arriving deck

\section{Compiling process of environment spectrum}

After determine the four kinds environment elements, according to the simplification and processing methods of environment aging data, the climate data processing software has been compiled. The application software achieve statistical processing of meteorological data in the environment database of the area, obtain a series of still environment spectrum such as the month spectrum, month cumulative spectrum and year cumulative spectrum. Compiling process of environment spectrum is shown as fig.3:
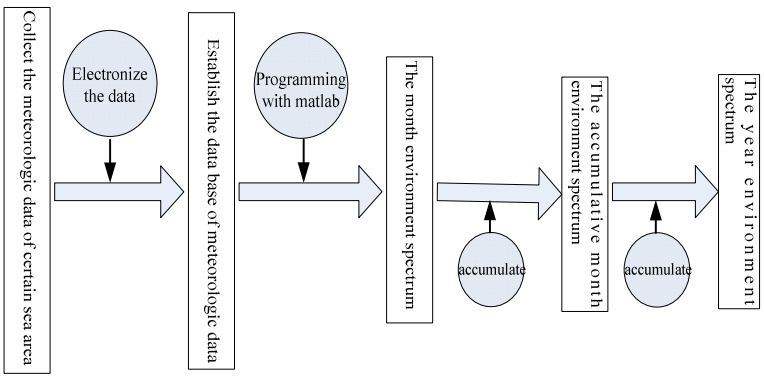

Figure.3 The flow chart for spectrum of environmental data

\section{CFRP MARINE ENVIRONMENT SPECTRUM}

\section{A. Month spectrum}

Present the corresponding rainfall time, rainfall and frequency, ultraviolet radiation, radiation time and the action time when the relative humidity is higher than $70 \%$ at the 7 temperature rating: $5^{\circ} \mathrm{C}, 10^{\circ} \mathrm{C}, 15^{\circ} \mathrm{C}, 20^{\circ} \mathrm{C}, 25^{\circ} \mathrm{C}$, $30^{\circ} \mathrm{C}, 35^{\circ} \mathrm{C}$. Program respectively according to the format and content of the original meteorological data.(the part of environment data in August 2013 is shown in table 2).

TABLEII. Some Statistics Of Environmental Dates In Aug.2013

\begin{tabular}{|c|c|c|c|c|c|c|c|}
\hline Date & $\begin{array}{c}\text { Time } \\
(24 \mathrm{~h})\end{array}$ & Latitude & Longitude & $\begin{array}{c}\text { Wave } \\
\text { height }(\mathrm{m})\end{array}$ & $\begin{array}{c}\text { Temperature } \\
\left({ }^{\circ} \mathrm{C}\right)\end{array}$ & $\begin{array}{c}\text { Sea level } \\
\text { pressure }\end{array}$ & $\begin{array}{c}\text { Humidity } \\
(\%)\end{array}$ \\
\hline \multirow{8}{*}{8.20} & 2 & $08^{\circ} 41^{\prime} \mathrm{N}$ & $52^{\circ} 26^{\prime} \mathrm{E}$ & 2 & 25.9 & 1012.3 & 92 \\
& 6 & $09^{\circ} 44^{\prime} \mathrm{N}$ & $52^{\circ} 14^{\prime} \mathrm{E}$ & 3 & 24.5 & 1011.2 & 91 \\
& 14 & $11^{\circ} 52^{\prime} \mathrm{N}$ & $51^{\circ} 51^{\prime} \mathrm{E}$ & 2.5 & 25.3 & 1010.3 & 80 \\
\hline 8.21 & 20 & $13^{\circ} 32^{\prime} \mathrm{N}$ & $51^{\circ} 12^{\prime} \mathrm{E}$ & 1.5 & 29.8 & 1006.0 & 83 \\
& 2 & $13^{\circ} 59^{\prime} \mathrm{N}$ & $50^{\circ} 52^{\prime} \mathrm{E}$ & 1 & 29.3 & & 81 \\
& 6 & $13^{\circ} 58^{\prime} \mathrm{N}$ & $50^{\circ} 51^{\prime} \mathrm{E}$ & 1 & 28.6 & 1007.3 & 86 \\
& 14 & $14^{\circ} 04^{\prime} \mathrm{N}$ & $50^{\circ} 48^{\prime} \mathrm{E}$ & 1 & 29.2 & 1006.8 & 84 \\
& 20 & $13^{\circ} 37^{\prime} \mathrm{N}$ & $49^{\circ} 48^{\prime} \mathrm{E}$ & 1 & 31.2 & & 76 \\
\hline
\end{tabular}


As for the temperature spectrum program, compile it with Mat-lab software and the program data is read as follows:

clear

for

$\mathrm{a}=$ xlsread('G: $\mid$ calculation\Dresult.xls','result','F2:F745')

for

b=xlsread('G: \calculation $\backslash$ Dresult.xls','result','H2:H745')

$\mathrm{A}=[]$

$\mathrm{c}=\operatorname{sum}((\mathrm{a}>=20 \& \mathrm{a}<25) \&(\mathrm{~b}>=70 \& \mathrm{~b}<80))$

$\mathrm{d}=\operatorname{sum}((\mathrm{a}>=20 \& \mathrm{a}<25) \&(\mathrm{~b}>=80 \& \mathrm{~b}<90))$

$\mathrm{e}=\operatorname{sum}((\mathrm{a}>=20 \& \mathrm{a}<25) \&(\mathrm{~b}>=90 \& \mathrm{~b}<100))$

$\mathrm{f}=\operatorname{sum}((\mathrm{a}>=25 \& \mathrm{a}<30) \&(\mathrm{~b}>=70 \& \mathrm{~b}<80))$

$\mathrm{g}=\operatorname{sum}((\mathrm{a}>=25 \& \mathrm{a}<30) \&(\mathrm{~b}>=80 \& \mathrm{~b}<90))$

$\mathrm{h}=\operatorname{sum}((\mathrm{a}>=25 \& \mathrm{a}<30) \&(\mathrm{~b}>=90 \& \mathrm{~b}<100))$

$\mathrm{i}=\operatorname{sum}((\mathrm{a}>=30 \& \mathrm{a}<35) \&(\mathrm{~b}>=70 \& \mathrm{~b}<80))$

$\mathrm{j}=\operatorname{sum}((\mathrm{a}>=30 \& \mathrm{a}<35) \&(\mathrm{~b}>=80 \& \mathrm{~b}<90))$

$\mathrm{k}=\operatorname{sum}((\mathrm{a}>=30 \& \mathrm{a}<35) \&(\mathrm{~b}>=90 \& \mathrm{~b}<100))$

$\mathrm{l}=\operatorname{sum}((\mathrm{a}>=35) \&(\mathrm{~b}>=70 \& \mathrm{~b}<80))$

$\mathrm{m}=\operatorname{sum}((\mathrm{a}>=35) \&(\mathrm{~b}>=80 \& \mathrm{~b}<90))$

$\mathrm{n}=\operatorname{sum}((\mathrm{a}>=35) \&(\mathrm{~b}>=90 \& \mathrm{~b}<100))$

$\mathrm{o}=\operatorname{sum}((\mathrm{a}>=0 \& \mathrm{a}<5) \&(\mathrm{~b}>=70 \& \mathrm{~b}<80))$

$$
\begin{aligned}
& \mathrm{p}=\operatorname{sum}((\mathrm{a}>=5 \& \mathrm{a}<10) \&(\mathrm{~b}>=70 \& \mathrm{~b}<80)) \\
& \mathrm{q}=\operatorname{sum}((\mathrm{a}>=10 \& \mathrm{a}<15) \&(\mathrm{~b}>=70 \& \mathrm{~b}<80)) \\
& \mathrm{r}=\operatorname{sum}((\mathrm{a}>=15 \& \mathrm{a}<20) \&(\mathrm{~b}>=70 \& \mathrm{~b}<80)) \\
& \mathrm{s}=\operatorname{sum}((\mathrm{a}>=0 \& \mathrm{a}<5) \&(\mathrm{~b}>=80 \& \mathrm{~b}<90)) \\
& \mathrm{t}=\operatorname{sum}((\mathrm{a}>=5 \& \mathrm{a}<10) \&(\mathrm{~b}>=80 \& \mathrm{~b}<90)) \\
& \mathrm{u}=\operatorname{sum}((\mathrm{a}>=10 \& \mathrm{a}<15) \&(\mathrm{~b}>=80 \& \mathrm{~b}<90)) \\
& \mathrm{v}=\operatorname{sum}((\mathrm{a}>=15 \& \mathrm{a}<20) \&(\mathrm{~b}>=80 \& \mathrm{~b}<90)) \\
& \mathrm{w}=\operatorname{sum}((\mathrm{a}>=0 \& \mathrm{a}<5) \&(\mathrm{~b}>=90)) \\
& \mathrm{x}=\operatorname{sum}((\mathrm{a}>=5 \& \mathrm{a}<10) \&(\mathrm{~b}>=90)) \\
& \mathrm{y}=\operatorname{sum}((\mathrm{a}>=10 \& \mathrm{a}<15) \&(\mathrm{~b}>=90)) \\
& \mathrm{z}=\operatorname{sum}((\mathrm{a}>=15 \& \mathrm{a}<20) \&(\mathrm{~b}>=90)) \\
& \mathrm{A}=[\mathrm{o}, \mathrm{p}, \mathrm{q}, \mathrm{r}, \mathrm{c}, \mathrm{f}, \mathrm{i}, \mathrm{i} ; \mathrm{s}, \mathrm{t}, \mathrm{u}, \mathrm{v}, \mathrm{d}, \mathrm{g}, \mathrm{i}, \mathrm{m} ; \mathrm{w}, \mathrm{x}, \mathrm{y}, \mathrm{z}, \mathrm{e}, \mathrm{h}, \mathrm{k}, \mathrm{n}] \\
& \text { end }
\end{aligned}
$$$$
\text { end }
$$

Use the program above, any single month temperature and humidity spectrum shall be compiled, for instance, the temperature and humidity spectrum in May 2009 is shown in table 3. By the same token, compile corresponding subroutine can obtain the single month rainfall spectrum and ultraviolet radiation spectrum.

TABLEIII. Temperature And Rrelative Humidity Spectrum At Certain Sea Area In May 2009

\begin{tabular}{|c|c|c|c|c|c|c|}
\hline $\begin{array}{c}\text { Temperature }\left({ }^{\circ} \mathrm{C}\right) \\
\text { Relative humidity }(\%)\end{array}$ & $5-10$ & $10-15$ & $15-20$ & $20-25$ & $25-30$ & $30-35$ \\
\hline $70-80$ & 0 & 0 & 0 & 21.35 & 117.4 & 166.7 \\
$80-90$ & 0 & 0 & 0 & 0 & 170.25 & 47.75 \\
$\geq 90$ & 0 & 0 & 0 & 11.34 & 0 & 0 \\
\hline Humid atmosphere $(\mathrm{RH} \geq 70 \%)$ & \multicolumn{7}{|c|}{534.79} \\
\hline
\end{tabular}

Note: date in the table is the action time of the corresponding temperature and relative humidity/h(the same with table 4 , table 5 and table 6 )

\section{B. Month Cumulative Spectrum}

Considering the environment elements in the certain month of each year is a random variable based on the month spectrum, obtain the monthly mean, standard deviation and statistics when the reliability is $90 \%$ over the years. The temperature and relative humidity cumulative spectrum is shown in table 4 :

TABLE IV.Temperature And Relative Humidity Spectrum At Certain Sea Area In Jan 2009

\begin{tabular}{|c|c|c|c|c|c|c|}
\hline $\begin{array}{c}\text { Temperature }\left({ }^{\circ} \mathrm{C}\right) \\
\text { Relative humidity }(\%)\end{array}$ & $5-10$ & $10-15$ & $15-20$ & $20-25$ & $25-30$ & $30-35$ \\
\hline $70-80$ & 0 & 0 & 0 & 315 & 12 & 0 \\
$80-90$ & 0 & 0 & 0 & 231 & 84 & 0 \\
$\geq 90$ & 0 & 0 & 0 & 45 & 9 & 0 \\
\hline Humid atmosphere $(\mathrm{RH} \geq 70 \%)$ & \multicolumn{7}{|c|}{696} \\
\hline
\end{tabular}

\section{Annual Spectrum}

Obtain each year's mean and statistics when the reliability is $90 \%$ based on the month spectrum statistics. As for the gulf of Aden, with an accumulative method on the basis of every month spectrum, the action rain spectrum(table5), annual temperature and relative humidity spectrum(table6), annual ultraviolet radiation, action time and its' proportion of the whole year in 2009 could be got. 
TABLEV. Rain Spectrum Of Certain Sea Area In 2009

\begin{tabular}{|c|c|c|c|c|}
\hline Temperature $\left({ }^{\circ} \mathrm{C}\right)$ & Rain period(h) & Annual rainfall(mm) & $\begin{array}{c}\text { Annual rainfall } \\
\text { frequency }\end{array}$ & $\begin{array}{c}\text { Proportion of } \\
\text { rainfall period(\%) }\end{array}$ \\
\hline $5-10$ & 0 & & & \\
$10-15$ & 0 & & & \\
$15-20$ & 10.3 & \multirow{2}{*}{141.9} & & \\
$20-25$ & 411.2 & & & \\
$25-30$ & 196 & & & \\
$30-35$ & 809.9 & & & \\
\hline Total & & & & \\
\hline
\end{tabular}

TABLEVI. Temperature And Relative Humidity Spectrum Of Certain Sea Area In 2009

\begin{tabular}{|c|c|c|c|c|c|c|}
\hline $\begin{array}{c}\text { Temperature }\left({ }^{\circ} \mathrm{C}\right) \\
\text { Relative humidity }(\%)\end{array}$ & $5-10$ & $10-15$ & $15-20$ & $20-25$ & $25-30$ & $30-35$ \\
\hline $70-80$ & 0 & 0 & 0 & 448.47 & 1164.53 & 1758.27 \\
$80-90$ & 0 & 0 & 0 & 1044.39 & 1331.23 & 191.67 \\
$\geq 90$ & 0 & 0 & 0 & 603.75 & 123.12 & 61.65 \\
\cline { 2 - 7 } & \multicolumn{7}{|c}{6727.08} \\
\hline
\end{tabular}

Annual ultraviolet radiation:5382.72MJ/m2; Radiation CFRP Marine environment spectrum of the area in table7 time:3015.7 h; Accounted for the proportion of and the histogram is shown in fig.4. time:34.4\%. Eventually, comprehensively obtain the

TABLEVII. Marine Environment Spectrum For CFRP Of Certain Sea Area

\begin{tabular}{|c|c|c|c|}
\hline Environment elements & Rainfall & Moist air & Ultraviolet radiation \\
\hline Action time $/ \mathrm{h}$ & 809.9 & 6727.08 & 3015.7 \\
Action & Rainfall: $1141.9 \mathrm{~mm}$ & - & Radiation: $5382.72 \mathrm{MJ} / \mathrm{m} 2$ \\
Action frequency & 85 & - & - \\
Percentage of time $/ \%$ & 9.27 & 76.79 & 34.4 \\
\hline
\end{tabular}

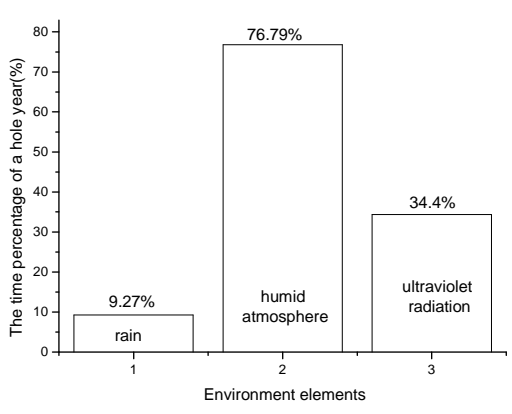

Figure. 4 Histogram of environment spectrum of certain sea area for CFRP

\section{ACKNOWLEDGMENT}

Compiling research on the environment of aircraft structure composite material using has been done on the basis of the research on composite material aging mechanism. The significant factors that have an impact on CFRP aging under the Marine environment are determined as follows: temperature, relative humidity, rainfall and ultraviolet radiation, the way of ship dynamic environment data collection has been used to collect hydrological meteorological data, and the method of simplification and processing of data is also be researched and presented. Then compile the Marine environment spectrum of aircraft structure composite material in the area with matalab according to the method mentioned above. This environment spectrum reflects the aging characteristics of environment in the area, and it can be applied to environmental adaptability evaluation.

\section{REFERENCE}

[1] Caodingguo, Rensanyuan, Wanghaowei. Equivalent Method of Using ESI for Corrosion Damage and Its Application[J]. Acta Aeronautica et Astronautica Sinica, 2008, 29(3): 634 639

[2] Ray.B C.Temperature effect during humid aging on interfaces of glass and carbon fibers reinforced epoxy composites[J].Journal of Colloid and Interface Science,2006,298:111 117.

[3] M L,Zhao Y,Xu F H,et al.Aging Advanced Polymer Matrix Composites I-Thermal aging[J]. Aeronautics,2000,21(4):62-65.

[4] Wang X J,Liang G Z,Zhang W.Impact on the performance of high-performance composite materials heat aging $[\mathrm{J}]$.Solid Rocket Technology,2006,29(3):301-304.

[5] Li X J,Xu F H,Chen X W.Advanced Polymer Matrix Composites [J]. Materials Engineering,1990(12): 19 22. 
[6] Oliveira.B F,Creus.G.J.An analytical-numerical framework for the study of aging in fiber reinforced polymer composites[J].Composite Structures,2004,65:443 457.

[7] Chenyueliang, Jinping, Lindianxiong Mj . Navy aircraft structure corrosion control and strength assessment . National Defence Industry Press, BeiJing: 2009

[8] Electronic Publication: Digital Object Identifiers (DOIs):
[9] D. Kornack and P. Rakic, "Cell Proliferation without Neurogenesis in Adult Primate Neocortex," Science, vol. 294, Dec. 2001, pp. 2127-2130, doi:10.1126/science.1065467.

[10] H. Goto, Y. Hasegawa, and M. Tanaka, "Efficient Scheduling Focusing on the Duality of MPL Representatives," Proc. IEEE Symp. Computational Intelligence in Scheduling (SCIS 07), IEEE Press, Dec. 2007, pp. 57-64, doi:10.1109/SCIS.2007.357670. 